\title{
A ALIMENTAC̄̃O COMO POLÍTICA SOCIAL AO LONGO DA HISTÓRIA DO IFRN: DA ESCOLA DE APRENDIZES ARTÍFICES DE NATAL À ESCOLA INDUSTRIAL DE NATAL
}

\author{
Gizelle Rodrigues dos Santos; Márcio Adriano de Azevedo \\ Instituto Federal de Educação, Ciência e Tecnologia do Rio Grande do Norte \\ DOI: 10.15628/rbept.2018.7179
}

Artigo submetido em Abril/2018 e aceito em Maio/2018

\begin{abstract}
RESUMO
O Instituto Federal de Educação, Ciência e Tecnologia do Rio Grande do Norte (IFRN), desde que foi criado, incorpora ações destinadas a fomentar a aprendizagem dos discentes, dentre elas, a alimentação. Selecionamos seus três precursores (Escola de Aprendizes Artífices de Natal, Liceu Industrial de Natal e Escola Industrial de Natal) que mantiveram o regime semi-interno em funcionamento, com o objetivo de investigar os meandros da oferta da alimentação escolar enquanto uma política social institucional. A metodologia está alicerçada na abordagem qualitativa e trata-se de uma pesquisa bibliográfica. Também buscamos nos relatos de ex-alunos de diferentes épocas da Instituição, contidos no Portal da Memória do IFRN, informações sobre a alimentação ofertada aos discentes. Evidenciamos uma grande escassez de fontes de informação, apesar das escolas profissionais da rede federal terem sido pioneiras na oferta de merenda escolar em 1922. Desde quando foi desenvolvido na Escola Industrial de Natal, o serviço social incorporou a oferta da alimentação como política voltada ao discente com baixo perfil socioeconômico visando fomentar a aprendizagem e garantir sua permanência. Assim, a alimentação passou a ser ofertada nas instituições estudadas enquanto uma política social voltada a promover o fomento à aprendizagem, embora não conseguisse impacto positivo sobre a alta evasão em virtude das múltiplas causas que influenciam este indicador.
\end{abstract}

Palavras-Chave: História. Alimentação. Escola de Aprendizes Artífices de Natal. Escola Industrial de Natal.

\section{T FOOD AS A SOCIAL POLICY THROUGH THE HISTORY OF IFRN: FROM ESCOLA DE APRENDIZES ARTÍFICES DE NATAL TO THE ESCOLA INDUSTRIAL DE NATAL}

\begin{abstract}
The Instituto Federal de Educação, Ciência e Tecnologia do Rio Grande do Norte (IFRN), since it was created, incorporates actions aimed at fostering students' learning, among them, food. We select your three precursors (Escola de Aprendizes Artífices de Natal, Liceu Industrial de Natal and Escola Industrial de Natal) that maintained the semi-internal regime in operation, with the objective of investigating the meanders of school food supply as an institutional social policy. The methodology is based on the qualitative approach and it is a bibliographical research. We also searched the reports of ex-students from different periods of the Institution, contained in the IFRN Memory Portal, information about the food offered to
\end{abstract}


students. We observed a great shortage of sources of information, although the professional schools of the federal network were pioneers in the provision of school meals in 1922. Since when it was developed in the Escola Industrial de Natal, the social service incorporated the food supply as a policy aimed at the student with low profile to promote learning and ensure its permanence. Thus, food became available in the institutions studied, while a social policy aimed at promoting a promotion of learning, although it did not have a positive impact on high evasion due to multiple causes that influence this indicator.

Keywords: History. Feed. Escola de Aprendizes Artífices de Natal. Escola Industrial de Natal.

\section{INTRODUÇÃO}

O Instituto Federal de Educação, Ciência e Tecnologia do Rio Grande do Norte (IFRN) atualmente compõe a Rede Federal de Educação Profissional, Ciência e Tecnologia que foi instituída a partir da Lei oㅜ 11.892, de 29 de dezembro de 2008 (BRASIL, 2008). Entretanto, ao longo de seu percurso histórico, passou por diferentes denominações além de mudanças em sua estrutura institucional. Inicialmente, foi criada como Escola de Aprendizes Artífices de Natal, em 1910 (GUIMARÃES; BARACHO, 1910), passando a Liceu Industrial de Natal, em 1937 (BRASIL, 1937), a Escola Industrial de Natal, em 1942 (BRASIL, 1942), Escola Técnica Federal do Rio Grande do Norte, em 1968 (PEGADO, 2010) e Centro Federal de Educação Tecnológica do Rio Grande do Norte, em 1999 (BRASIL, 1999).

Desde que foi constituída, a Instituição incorpora ações destinadas a fomentar a aprendizagem dos discentes, dentre elas, a alimentação. Até 1964, enquanto esteve em vigor o regime de semi-internato, tanto a Escola de Aprendizes Artífices de Natal, quanto o Liceu Industrial de Natal e a Escola Industrial de Natal (EIN) desenvolveram um programa de alimentação no intuito de garantir refeições diárias para os alunos que necessitavam permanecer na escola durante os dois turnos em que estavam em aula ou desenvolvendo atividades didáticas complementares. Para além da necessidade fisiológica, a oferta da alimentação visava aplacar a fome de um alunado cujo perfil socioeconômico era oriundo, prioritariamente, de famílias de menor renda, constituindo-se como uma importante ferramenta social de gestão do ensino.

Dessa forma, para este artigo, selecionamos os três estabelecimentos de ensino anteriormente referidos que mantiveram o regime semi-interno em funcionamento, com o objetivo de investigar os meandros da oferta da alimentação escolar enquanto uma política social institucional.

Estudos que envolvam o tema são relevantes devido à importância que as políticas públicas voltadas tanto à educação profissional quanto à segurança alimentar e nutricional têm tomado no século XXI, além do que a riqueza histórica pode nos revelar, de modo que trabalhos dessa natureza 
podem nos permitir uma melhor compreensão das práticas atuais do IFRN por meio do reflexo de sua atuação pregressa.

\section{METODOLOGIA}

Como base de nossa investigação, Bloch (1993) nos instiga à reflexão sobre o sentido da história não como simples ciência do passado, mas como o resultado de um vai e vem constante do historiador, do passado ao presente e do presente ao passado.

Além disso, adotamos a concepção de que "fundada sobre o corte entre um passado, que é seu objeto, e um presente, que é o lugar de sua prática, a história não para de encontrar o presente no seu objeto, e o passado, nas suas práticas." (CERTEAU, 2014, p. 46).

Dessa forma, a metodologia adotada para a elaboração deste texto está alicerçada na abordagem qualitativa e trata-se de uma pesquisa bibliográfica.

Conceitualmente, na abordagem qualitativa, o pesquisador procura se aprofundar na compreensão dos fenômenos que estuda, ações dos indivíduos ou grupos em seu ambiente e contexto social (ALVES, 1991). Na revisão da literatura de um trabalho científico, buscam-se todas as pesquisas disponíveis no intuito de selecionar o que possa ser utilizável em seu estudo, à procura dos saberes e trabalhos relacionados com sua questão (LAVILLE; DIONE, 1999). Severino (2007) ressalta que a internet tornou-se uma fonte de pesquisa primordial de dados científicos, pela facilidade de acesso.

Ao percebermos a complexidade de um trabalho que se reporta a uma trajetória, também entendemos que a pesquisa qualitativa, calcada na observação e na leitura da teoria, deve se debruçar sobre o que não está explícito nos acontecimentos, partindo das pistas e sinais que são deixados a fim de compreender os fatos.

Assim, pela escassez de trabalhos escritos, também buscamos nos relatos de ex-alunos de diferentes épocas da Instituição contidos no Portal da Memória - atividade que foi parte integrante do Projeto A Caminho do Centenário, que comemorou em 2009 os cem anos do, hoje, IFRN (INSTITUTO FEDERAL DE EDUCAÇÃO, CIÊNCIA E TECNOLOGIA DO RIO GRANDE DO NORTE, 2009) - informações sobre a alimentação ofertada aos discentes.

A seguir, apresentamos o percurso histórico do lapso temporal escolhido para análise traçado pela instituição que compõe nosso estudo evidenciando as minúcias pela qual a oferta de sua alimentação passou. 


\section{A ALIMENTAÇÃO ESTUDANTIL: DA ESCOLA DE APRENDIZES ARTÍFICES DE NATAL À ESCOLA INDUSTRIAL DE NATAL}

Criadas por meio do Decreto ㄲo 7.566, de 23 de setembro de 1909, durante o governo do Presidente da República Nilo Peçanha, as 19 Escolas de Aprendizes Artífices objetivavam dar educação primária e profissional, ensinando ofícios, e acolher jovens entre 10 e 13 anos das classes proletárias (BRASIL, 1909).

Em 03 de janeiro de 1910, foi instalada a Escola de Aprendizes Artífices de Natal (GUIMARÃES; BARACHO, 2010) que se situava na Rua Presidente Passos, Cidade Alta, no prédio onde atualmente está localizada a Casa do Estudante. Funcionava inicialmente em regime de externato (GURGEL, 2007), posteriormente, em semi-internato e possuía oficinas de marcenaria, sapataria, alfaiataria, serralharia e funilaria. Em 1914, a Escola transferiu-se para a Avenida Rio Branco, 743, Cidade Alta (PEGADO, 2010). Tendo em vista o regime de semi-internato, a oferta da alimentação era necessária, como perceberemos no transcorrer do texto.

Com a nova regulamentação, mediante o Decreto № 9.070 , de 25 de outubro de 1911, a faixa etária mudou para 12 anos no mínimo e 16 no máximo (BRASIL, 1911). Nos primeiros anos de funcionamento, as matrículas eram insignificantes e a evasão dos estudantes era grande. Uma das explicações para esse fato era a necessidade de os filhos trabalharem desde criança para auxiliar os pais (PEGADO, 2010).

Como tinha uma clientela de baixa condição socioeconômica, a Escola deveria proporcionar-lhe as condições mínimas para a aprendizagem, mas isso não ocorreu, tendo em vista que o regime de externato, a princípio, não fornecia alimentação a seus alunos, embora esses seguissem uma rígida rotina de aulas e produção nas oficinas (GURGEL, 2007).

De acordo com L. Silva (2016), o ensino profissional nas Escolas de Aprendizes Artífices seguiu por 20 anos sem alcançar os objetivos propostos. Diante desse quadro, o Ministério da Agricultura, Indústria o Comércio, órgão ao qual essas escolas eram então vinculadas, instituiu, em 1920, a Comissão de Remodelação do Ensino Profissional Técnico (CREPT) no intuito de reformar a instrução ofertada por essas instituições. Constando no plano de ação de tal comissão, cujas inovações julgava indispensáveis e urgentes, estava a oferta de merenda escolar.

Fruto dessa conjuntura, o Ministro da Agricultura, Indústria e Comércio emitiu uma portaria, assinada em 26 de setembro de 1922, garantindo a alimentação aos discentes das escolas profissionais da rede federal como uma das estratégias para manter os alunos nessas instituições (SILVA, M., 2012). Inovadora, haja vista que a alimentação escolar brasileira foi instituída somente em 31 de março de 1955, por meio do Decreto no 37.106 (BRASIL, 
1955), tal medida buscava reforçar nos aprendizes, provenientes das camadas populares, o desejo de frequentar as Escolas. De fato, esse objetivo foi alcançado, pois, conforme João Lüderitz, coordenador dos trabalhos da CREPT, foi "deveras notável o aumento da frequência nas escolas com a distribuição da sopa ao meio dia" (FONSECA, 1986, p. 206 apud SILVA, L., 2016, p. 93-94).

Em relatório emitido pelo serviço de Remodelação, afirmou-se, quanto à distribuição da merenda aos alunos do turno diurno, que foi uma das causas para o aumento da matrícula e permanência dos aprendizes nas Escolas do país: "A merenda escolar distribuida aos alumnos não só tem cooperado para 0 desenvolvimento physico dos aprendizes mais desfavorecidos, como tem contribuido efficazmente para o equilíbrio da frequencia" (BRASIL, 1927, p. 257).

A despeito das medidas adotadas pela CREPT, a evasão dos estudantes era grande, havendo como uma das explicações a necessidade de os alunos, ao aprenderem as primeiras lições nas oficinas, terem de trabalhar para se autossustentar e a suas famílias (SILVA, L., 2016), comprovando que não somente as ações internas dos estabelecimentos estudantis são suficientes para a garantia da permanência do estudante na escola, pois as causas da evasão são multifatoriais.

Na perspectiva de uma ação inclusiva, para Sobottka (2006, p. 80), sob a ótica da mobilidade social,

[...] cabe à política social a equiparação, até certo grau, das
condições de vida, desvinculando a distribuição social das
oportunidades da origem das pessoas. Ou seja, ela tem como
tarefa fazer com que as características adscritas não se imponham
como limitação determinante do horizonte de possibilidades de
construção da biografia social.

Assim, percebemos como a alimentação não se constituiu como fator suficiente de permanência, sendo necessárias outras políticas que promovessem a redução da evasão.

Em face da instalação do Governo Provisório de Getúlio Vargas, em 1930, a CREPT foi extinta e substituída, no ano seguinte, pela Inspetoria do Ensino Profissional Técnico, vinculada ao recém-criado Ministério da Educação e Saúde Pública, para o qual foram transferidas as escolas de aprendizes artífices do país. Por ocasião da passagem da direção da Escola ao escriturário Luiz Gonzaga de Carvalho, o jurista Floriano Cavalcanti de Albuquerque relatou a situação de incerteza vivenciada pela Escola de Aprendizes Artífices de Natal, em meados de novembro de 1930, afirmando que: "[...] Suspendi todas as despezas, excepto duas ou três por indispensáveis, como: fornecimento da merenda, de exigência regulamentar e cuja suspensão importaria na baixa absoluta da frequencia, se não mesmo no seu desapparecimento [...]" (ALBUQUERQUE, 1930 apud MEDEIROS, 2011, p. 28). 
Constatamos como, mesmo não estando correlacionada à taxa de evasão, havia nos relatos presentes nas bibliografias pesquisadas a convergência entre a oferta da alimentação e a frequência estudantil.

A mudança de denominação para Liceu Industrial de Natal integrou a reforma instituída pela Lei $\mathrm{n} .$. 378, de 13 de janeiro de 1937, do Ministério da Educação e Saúde Pública (BRASIL, 1937). Consta em seus horários de distribuição das aulas dos $1^{\circ}, 2^{\circ}, 3^{\circ}$ e $6^{\circ}$ anos, referentes ao ano de 1938 , a inserção do horário da merenda escolar entre as 11h30min e as 12h30min (GURGEL, 2007).

Tácito Costa, que foi aluno da oficina de alfaiataria da instituição entre o final da década de 1930 e início da década de 1940, expôs o momento de entrada no refeitório para a oferta da alimentação, também marcado pela rígida disciplina acadêmica existente em todos os ambientes estudantis e relatada por alunos de diferentes épocas: "Pra gente entrar no refeitório, tinha que estar na fila, existia uma batidinha de um sino e tinha que estar já na fila [...]". (INSTITUTO FEDERAL DE EDUCAÇÃO, CIÊNCIA E TECNOLOGIA DO RIO GRANDE DO NORTE, 2009, on-line).

Por meio do Decreto-Lei № 4.127, de 25 de fevereiro de 1942, a Instituição mudou sua estrutura de Liceu Industrial para Escola Industrial de Natal (BRASIL, 1942). Durante essa época, houve um pico de desenvolvimento econômico no Rio Grande do Norte decorrente do envolvimento do Brasil na II Guerra Mundial e da consolidação americana do Quartel General do Atlântico Sul na Base Aérea de Parnamirim field que, na época, pertencia à Natal. $O$ envolvimento deste estado com a guerra influenciou também o cotidiano da Escola Industrial, como a alteração do horário das aulas, para que a comunidade acadêmica pudesse chegar às suas casas antes do apagar das luzes, o chamado black out. Nessa mesma época, também foi adquirido o terreno e iniciadas as obras do atual Campus Natal-Central (PEGADO, 2010).

Nesse período, a diferença entre o número de alunos matriculados nas séries iniciais e aqueles matriculados, sobretudo, na última série, podia atingir índices superiores a 50\%. Em uma análise inicial, M. Silva (2012) observou na Escola que a evasão era um fato já constatado no início dos anos de 1940, que se repetia nos anos de 1950, apesar das medidas tomadas para garantir a permanência discente como, por exemplo, a sondagem inicial das aptidões dos alunos para a prática de um ofício em um determinado curso, a garantia de alimentação e a distribuição do fardamento e material escolar.

Em que pese a importância dessas medidas, elas não eram suficientes para solucionar um problema que também estava relacionado à realidade social vivida pelos alunos, caracterizada pela ausência de condições econômicas capazes de atender às necessidades do grupo do qual faziam parte. Essa situação certamente contribuía para que o aluno, antes do término do curso, priorizasse o desenvolvimento de alguma atividade no 
campo profissional (SILVA, M., 2012), comprovando que não somente uma política social institucional é suficiente para garantir a permanência do discente na escola, mas que as condições de vida fora dela são solidamente determinantes.

Quanto ao espaço físico ocupado pela EIN, teriam existido reformas e adequações dos ambientes para viabilizar as ações educativas, mas, a priori, seria o mesmo utilizado desde a Escola de Aprendizes Artífices de Natal (SILVA, M., 2012).

Assim, vejamos a seguir a Figura 1 que contém a planta baixa do pavimento térreo da Escola.

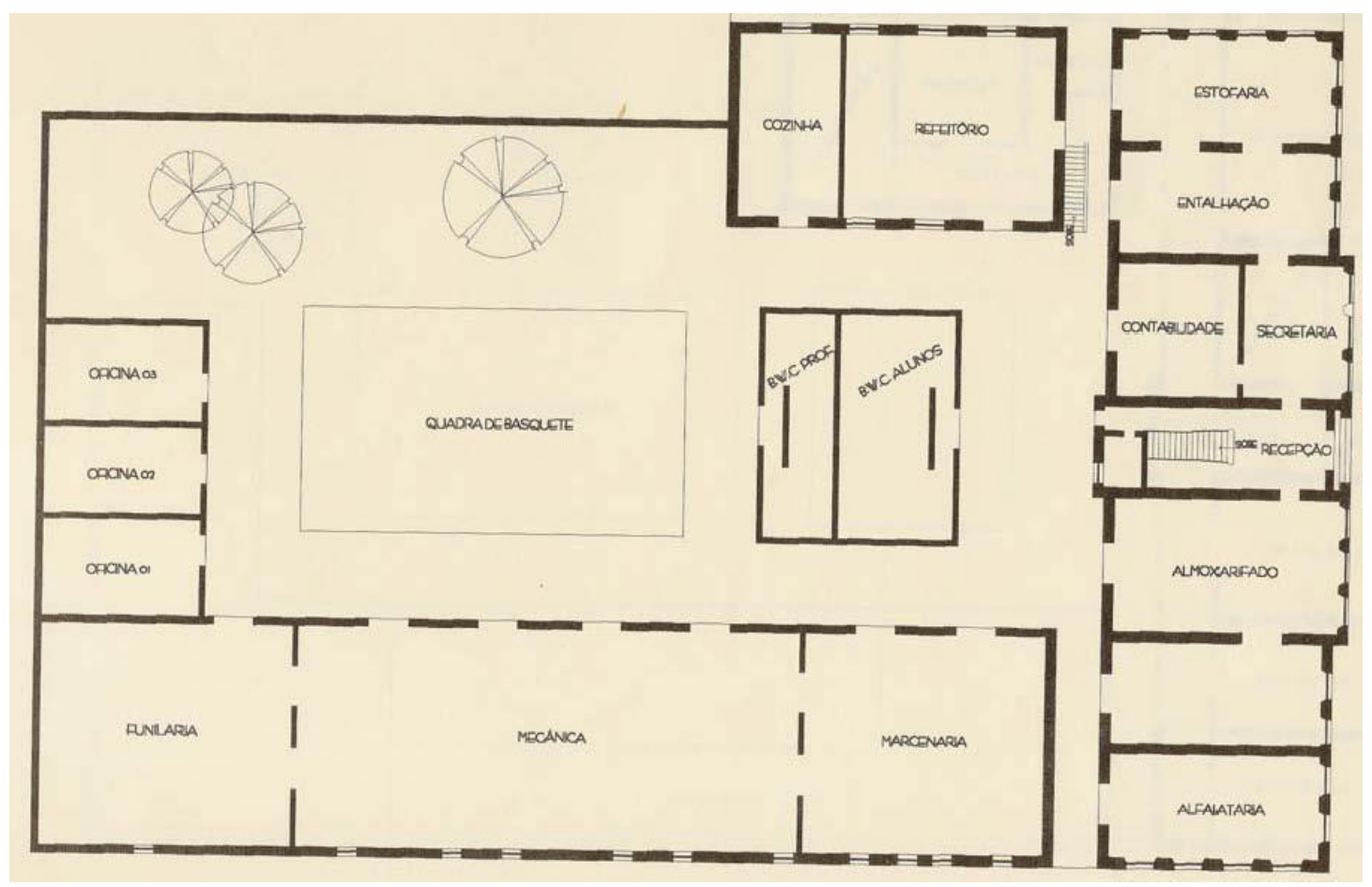

Figura 1: Planta baixa do pavimento térreo. 194?

Fonte: Gadelha (2007) apud M. Silva (2012).

Reportando-se à figura, M. Silva (2012) atenta para o fato de que, na definição desses espaços, não apenas as necessidades pedagógicas eram levadas em conta, pois alguns lugares foram constituídos para o atendimento assistencial dos alunos. No caso do pavimento térreo, a cozinha e o refeitório foram organizados para a oferta do serviço de alimentação como uma das estratégias definidas para tentar garantir maior permanência dos alunos na escola e, com isso, reduzir os altos índices de evasão.

Quanto à rotina da alimentação na EIN, Severino do Ramo, ex-aluno e professor aposentado, considerado a memória viva da instituição, explicou que (MEDEIROS, 2011, p. 39): 
[...] Depois da educação física nós íamos pra escola e nos preparávamos pra tomar café [...] servido, impreterivelmente, às $7 \mathrm{~h} 15 \mathrm{~min}$. Então, todos nos colocávamos na fila, por série, da $1^{\mathrm{a}}$ à $4^{\text {a }}$ série, e depois os alunos de Mestria [...]. Depois do café, éramos divididos pra irmos pras aulas teóricas [...]. No turno inverso, você ia pras oficinas, aí passava a tarde toda lá. Então nós chegávamos à escola muito cedo e saíamos às 5 horas da tarde. Além do café da manhã, você tinha às 10 horas um lanche, às 11h30min, o almoço, às $15 \mathrm{~h}$ outro lanche [...]. Então nossa vida era como alunos semiinternos. Só não fazíamos dormir na escola.

Pelo exposto, percebemos o salto que houve quanto ao número de refeições ofertadas pela EIN, quatro ao todo, quando comparamos ao que era inicialmente oferecido aos alunos da Escola de Aprendizes Artífices, uma refeição, tendo como preparação a sopa, no horário do almoço.

Neste contexto, em entrevista, o ex-aluno João Maria Cortez Gomes de Melo, afirmou que: "A gente não comprava nada de alimentação, a Escola dava tudo... aqueles pratos de papelão, metia farinha nas beiradas pra não derramar, né? (risos)... coisa assim, com fartura, que todo mundo se alimentava e ainda sobrava." (MEDEIROS, 2011, p. 45).

A firme disciplina escolar também esteve presente nos momentos das refeições. Maurílio Pinto, ex-aluno da antiga oficina de alfaiataria entre 1957 e 1959, ilustrou expondo que: "[...] por exemplo, o refeitório, cada mesa daquela tinha um aluno que era responsável pela mesa e imprimia muito respeito. (INSTITUTO FEDERAL DE EDUCAÇÃO, CIÊNCIA E TECNOLOGIA DO RIO GRANDE DO NORTE, 2009, on-line).

Em outro período, já como reflexo do momento político nacional, a mensagem de Erivan Sales do Amaral, que entrou na Escola Industrial para fazer o curso industrial básico, revelou: "[...] a ditadura com todo gás, fila para tudo que você imaginasse, fila pra tomar banho após a educação física, fila para o café da manhã, fila pra hora da "xepa" [...]". (INSTITUTO FEDERAL DE EDUCAÇÃO, CIÊNCIA E TECNOLOGIA DO RIO GRANDE DO NORTE, 2009, on-line)

Presente na tese de M. Silva (2012), o relato do ex-aluno Joaquim Elói Ferreira da Silva, ao se referir a sua participação no Corpo de Vigilantes, destacou que as reuniões ocorridas no intervalo do almoço, com o objetivo de avaliar e definir as punições cabíveis aos alunos que descumpriam as normas disciplinares constituía o Tribunal de Penas, a exemplo do modelo adotado pela justiça, com alunos ocupando o lugar que caberia aos jurados, promotor e advogado de defesa. Assim, o aluno inquirido tinha o direito a se defender junto aos colegas. Esse fato suscita pensar no que é assinalado por Faria Filho (2001, p. 70), sobre a organização de "uma rede de punições e recompensas, de forma que, em qualquer lugar ou a qualquer momento, a criança estivesse sujeita a uma observância e julgamento de seu caráter e de sua conduta.", valendo, inclusive, para o momento das refeições.

Dessa forma, para M. Silva (2012, p. 181), 
o espaço do refeitório na EIN se transformou num templo de diversas possibilidades de aprendizagem e controle: o acesso nos horários dos lanches e almoço somente era realizado após a organização dos alunos em filas. Em seu interior, as mesas já estavam previamente definidas e cada uma delas era controlada por dois alunos, geralmente das últimas séries, que assumiam a função de presidente e vice. Esses alunos eram os responsáveis pela garantia do silêncio em cada mesa e pela autorização para o início da refeição.

Segundo Camelo e Moura (2010), compondo a administração institucional da EIN para viabilizar a alimentação estudantil estavam os chefes de cozinha, os supervisores de refeitórios e o inspetor de alunos. Sobre este último, os autores afirmam que tinha uma atuação marcante na condução das atividades acadêmicas, considerando seu papel de orientador e organizador das tarefas, tanto que, a esse respeito, em depoimento, o professor Severino do Ramo de Brito, que foi aluno da Escola Industrial na década de 1940, ressaltou que "o inspetor de aluno determinava o aluno que seria responsável para administrar a mesa no refeitório" (CAMELO; MOURA, 2010, p. 80). Assim, percebe-se "por um lado, a postura autoritária do gestor, por não oportunizar uma escolha democrática, mas, por outro lado, um exemplo inequívoco de potencialização do valor da responsabilidade pelos espaços de uso coletivo, pelo espaço público" (CAMELO; MOURA, 2010, p. 80).

Apesar de já existirem ações voltadas, sobretudo, aos alunos mais pobres desde a criação da Instituição, a inserção do serviço social na Escola Industrial somente se deu em 1962 pelo Decreto oㅜ 994, no entanto, pautada em uma abordagem assistencialista e limitada, ainda comum nas escolas (SILVA, M., 2012).

Em entrevista concedida à M. Silva (2012, p. 50), a Assistente Social da instituição, Maria Duarte de Carvalho, afirmou que, nos anos de 1960,

[...], era visível a baixa condição econômica da maioria dos alunos
da Escola Industrial de Natal. A assistência social era a estratégia
utilizada pela Instituição para garantir a permanência deles na
Escola, que se materializava através da oferta da alimentação, do
fardamento e material escolar, além da assistência médica e
dentária e de bolsas concedidas pela Caixa Escolar aos que
comprovassem certo nível de carência.

Assim, a oferta da alimentação foi uma política incorporada ao serviço social como ação voltada ao discente com baixo perfil socioeconômico visando fomentar a aprendizagem e garantir sua permanência.

Como explica Medeiros (2011), o Plano Trienal de Educação do governo João Goulart (1963-65) previa utilizar melhor os recursos ociosos, diversificar as modalidades de ensino e ampliar as matrículas da rede nacional de escolas técnicas e industriais. Para isso, deveriam ser viabilizados cursos técnicos para graduados em ginásios comuns e cursos vespertinos e noturnos de capacitação profissional para o pessoal da indústria, sem exigência de formação acadêmica, entre outras iniciativas. 
O Plano Trienal parecia enfatizar, entretanto, a implantação de uma rede nacional de 600 ginásios industriais e 230 colégios modernos, distribuídos, prioritariamente, entre os 1.500 municípios brasileiros que não contassem com qualquer estabelecimento escolar de nível médio (MEDEIROS, 2011).

Resultou, provavelmente, desse investimento a diminuição das dotações orçamentárias às escolas técnicas e industriais na parte não referente ao pessoal, naquele início da década de 1960, forçando, no caso da EIN, a sacrificar a verba destinada à alimentação dos alunos. Na contramão da restrição orçamentária, as matrículas elevaram-se a 574 alunos, em 1964, com 488 estudantes matriculados nos cursos industriais e 86 nos cursos técnicos. O problema da falta de espaço foi contornado suprimindo-se o Salão de Honra, o salão de recreação e parte do refeitório (MEDEIROS, 2011).

Pelo exposto, percebemos como a expansão das matrículas e de espaço físico para viabilizar as aulas para esses novos alunos foram conseguidos, dentre outros, pela redução da oferta de alimentação aos alunos semi-internos.

$\mathrm{Na}$ pesquisa de M. Silva (2012), evidenciou-se que, em reunião ocorrida em 13 de março de 1963, o então Diretor da EIN, Irineu Martins de Lima, anunciou que: "com o corte de verbas e o aumento de alunos, a Escola não fornecerá almoço para a primeira série [...]" (SILVA, M., 2012, p. 127). Essa medida de contenção de gastos atingiu quase a metade dos alunos, haja vista a existência de 250 matrículas na $1^{\underline{a}}$ série do Ginásio Industrial registradas no Livro de Matrículas do ano 1963 (SILVA, M., 2012).

M. Silva (2012) também afirma que, diante dessa redução dos benefícios sociais, é possível que os alunos tenham apresentado alguma reação, o que deve ter gerado problemas relacionados ao descumprimento das normas disciplinares, pois na reunião do dia 19 de junho de 1963 com os professores, o diretor Pedro Martins de Lima alegou que estaria havendo entre os estudantes um pouco de falta de compreensão (SILVA, M., 2012, p. 128):

[...], talvez seja por efeito da redução do suprimento que houve este ano, em todos os setores, e que atingiu os alunos que estavam habituados a ter de tudo e viram-se de repente com quase nada materialmente. O que nos preocupa é que se tudo continuar assim, no segundo semestre não haverá distribuição de alimentos.

De antemão, acreditamos que fome e compreensão são substantivos que não cabem no mesmo contexto. Ademais, os alunos da Instituição não estavam tendo nada mais do que uma reação de sobrevivência e exigindo da Escola a qualidade de outrora, sobretudo quanto à oferta de uma necessidade humana básica, que é a alimentação.

Pelo exposto, questionamo-nos como ocorreu a manutenção dos alunos das classes mais pauperizadas estudando dois períodos na Instituição 
sem a oferta de uma refeição como o almoço. Também aventamos se houve coincidência quanto ao fim do regime de semi-internato no ano seguinte ao das medidas acima referidas, em 1964, além da indagação de que se a reação dos alunos às medidas de austeridade também não teria feito com que o regime semi-interno chegasse ao fim.

Posteriormente, em reunião ocorrida no início do mês de março de 1964, o então Diretor comunica o seu deslocamento até o Ministério da Educação para solicitar verbas, sobretudo, para a construção do novo prédio da escola, localizado no bairro do Tirol. Conforme M. SILVA (2012), era provável que ainda persistisse a manutenção de cortes na alimentação e na distribuição da farda e dos livros. Com isso, acreditamos que, em vez do foco na construção do novo prédio, não seria mais sensata a solicitação integral de recursos para a manutenção da Instituição em funcionamento?

Com o fim do regime de semi-internato, em 1964, cada turma foi distribuída em um único turno, ampliando a possibilidade de aumento de matrículas. Nesse sentido, os anos seguintes confirmaram o crescimento do número de alunos na EIN (SILVA, M., 2012). Desse modo, compreendemos que a existência do tempo parcial, implicando na necessidade da oferta de menos refeições, estaria em consonância com a contenção de verbas que necessitou ser feita pela EIN, corroborada, inclusive, pela supressão de parte do seu refeitório.

Em 1968, a EIN deixa de existir para dar lugar à Escola Técnica Federal do Rio Grande do Norte, inaugurando outro ciclo de mudanças para a Instituição (PEGADO, 2010).

\section{CONCLUSÃO}

Evidenciamos uma grande escassez de fontes de informação bibliográfica quanto à política de alimentação estudantil nas instituições precursoras do IFRN ao longo do lapso temporal escolhido para a pesquisa, apesar das escolas profissionais da rede federal terem sido pioneiras na oferta de merenda escolar em 1922.

Constatamos como, inicialmente, a alimentação começou a ser oferecida na Escola de Aprendizes Artífices de Natal na forma de uma sopa no horário do almoço e chegou à oferta máxima de quatro refeições ao longo dos dois turnos de aula na EIN.

Como nos demais ambientes escolares, a rígida disciplina acadêmica também se fazia presente nos locais de alimentação, sobretudo no espaço do refeitório da EIN.

Ademais, desde quando foi desenvolvido na EIN, o serviço social incorporou a oferta da alimentação como política voltada ao discente com 
baixo perfil socioeconômico visando fomentar a aprendizagem e garantir sua permanência.

Percebemos como na Escola de Aprendizes Artífices de Natal e no Liceu Industrial de Natal existiu um esforço para se manter uma regularidade na oferta da alimentação discente, ao contrário do constatado na EIN, pois no início da década de 1960, frente à expansão de matrículas acompanhada pela redução de verba na parte não referente ao pessoal, optou-se por contingenciar a alimentação dos alunos semi-internos, além de reduzir o espaço destinado ao consumo das refeições.

Assim, para além de uma necessidade fisiológica humana, a alimentação passou a ser ofertada nas instituições estudadas enquanto uma política social voltada a promover, sobretudo aos alunos mais pauperizados, um fomento à aprendizagem, embora não conseguisse impacto positivo sobre a alta evasão em virtude das múltiplas causas que influenciam este indicador, muitas delas alheias à escola.

\section{REFERÊNCIAS}

ALVES, Alda Judith. 0 planejamento de pesquisas qualitativas em educação. Cadernos de Pesquisa, São Paulo, v. 77, p. 53-61, maio, 1991. Disponível em: <http://publicacoes.fcc.org.br/ojs/ index.php/cp/article/view/1042/1050 >. Acesso em: 18 mar. 2018.

BLOCH, Marc. Introdução à História. Lisboa: Publicações EuropaAmérica. 1993.

BRASIL. Decreto de 18 de janeiro de 1999. Dispõe sobre a implantação do Centro Federal de Educação Tecnológica do Rio Grande do Norte CEFET/RN, e dá outras providências. Diário Oficial [da] República Federativa do Brasil, Brasília, DF, 19 jan. 1999. Disponível em: <https://www.planalto.gov.br/ccivil_03/dnn/anterior\%20a\%202000/1999/dnn79 33. htm >. Acesso em: 03 abr. 2018.

Decreto no 7.566, de 23 de setembro de 1909. Créa nas capitaes dos Estados da Escolas de Aprendizes Artífices, para o ensino profissional primario e gratuito. Republica dos Estados Unidos do Brazil, Rio de Janeiro, RJ, 23 set. $1909 . \quad$ Disponível em: <http://portal.mec.gov.br/setec/arquivos/pdf3/decreto_7566_1909.pdf>. Acesso em: 18 mar. 2018.

Decreto no 9.070, de 25 de outubro de 1911. Dá novo regulamento ás escolas de aprendizes artifices. Diário Oficial [da] República dos Estados Unidos do Brasil, Rio de Janeiro, RJ, Seção 1, 27 out. 1911. Disponível em: <http://www2.camara.leg.br/legin/fed/decret/1910-1919/decreto-9070-25- 
outubro-1911-525591-publicacaooriginal-1-pe.html>. Acesso em: 18 mar. 2018.

Decreto-Lei no 4.127, de 25 de fevereiro de 1942. Estabelece as bases de organização da rede federal de estabelecimentos de ensino industrial. Diário Oficial [da] República dos Estados Unidos do Brasil. Seção 1, p. 2957. Rio de Janeiro, RJ, 27 fev. 1942. Disponível em: <http://www2.camara.leg.br/legin/fed/declei/1940-1949/decreto-lei-4127-25fevereiro-1942-414123-publicacaooriginal-1-pe.html>. Acesso em: 18 mar. 2018.

Lei no 11.892, de 29 de Dezembro de 2008. Institui a Rede Federal de Educação Profissional, Científica e Tecnológica, cria os Institutos Federais de Educação, Ciência e Tecnologia, e dá outras providências. Diário Oficial [da] República Federativa do Brasil, Brasília, DF, 30 dez. 2008. Disponível em: $\quad<$ http://www.planalto.gov.br/ccivil_03/_ato20072010/2008/lei/l11892.htm>. Acesso em: 03 abr. 2018.

Lei no 378, de 13 de Janeiro de 1937. Dá nova organização ao Ministério da educação e Saúde Pública. Diário Oficial [da] República dos Estados Unidos do Brasil. Seção 1, p. 1210. Rio de Janeiro, RJ, 15 jan. 1959. Disponível em: <http://www2.camara.leg.br/legin/fed/lei/1930-1939/lei-378-13janeiro-1937-398059-publicacaooriginal-1-pl.html>. Acesso em: 18 mar. 2018.

Presidência da República. Decreto no 37.106, de 31 de março de 1955. Institui a companhia de Merenda Escolar. Diário Oficial [da] República dos Estados Unidos do Brasil, Rio de Janeiro, RJ, 02 abr. 1955. Disponível em: $\quad<$ http://www2.camara.leg.br/legin/fed/decret/1950-1959/decreto-3710631-marco-1955-332702-publicacaooriginal-1-pe.html>. Acesso em: 21 mar. 2018.

Relatório do Serviço de Remodelação: 1927. Disponível em: <http://brazil.crl.edu/bsd/bsd/u2023/000253.html>. Acesso em: 21 mar. 2018.

CAMELO, Gerda Lúcia Pinheiro; MOURA, Dante Henrique. Interfaces legais, políticas, pedagógicas e administrativas na trajetória do CEFET-RN. In: PEGADO, Erika Araújo da Cunha (Org.). A trajetória do CEFET-RN desde a sua criação no início do século $X X$ ao alvorecer do século $X X I$, Natal: IFRN Editora, 2. ed., 2010. 132 p. Disponível em: $<$ http://portal.ifrn.edu.br/pesquisa/editora/livros-em-pdf/a-trajetoria-do-cefetrn>. Acesso em: 18 mar. 2018.

CERTEAU, Michel de. A Invenção do Cotidiano: artes de fazer. 21. ed. Petrópolis, RJ: Vozes, 2014.

FARIA FILHO, Luciano Mendes de. República, Trabalho e Educação: a experiência do Instituto João Pinheiro (1909-1934). Bragança Paulista: Editora da Universidade São Francisco, 2001.

GUIMARÃES, Josiana Liberato Freire; BARACHO, Maria das Graças. Percurso educacional do CEFET-RN desde as origens aos dias atuais. 
In: PEGADO, Erika Araújo da Cunha (Org.). A trajetória do CEFET-RN desde a sua criação no início do século XX ao alvorecer do século XXI, Natal: IFRN Editora, 2. ed., 2010. 132 p. Disponível em: $<$ http://portal.ifrn.edu.br/pesquisa/editora/livros-em-pdf/a-trajetoria-do-cefet$\mathrm{rn}>$. Acesso em: 18 mar. 2018.

GURGEL, Rita Diana de Freitas. A trajetória da Escola de Aprendizes Artífices de Natal: república, trabalho e educação (1909-1942). 2007, 230f. Tese (Doutorado em Educação)- Universidade Federal do Rio Grande do Norte, 2007.2 Disponível em: <http://repositorio.ufrn.br:8080/jspui/bitstream/123456789/14146/1/RitaDFG.p df>. Acesso em: 21 mar. 2018.

INSTITUTO FEDERAL DE EDUCAÇÃO, CIÊNCIA E TECNOLOGIA DO RIO GRANDE DO NORTE. Portal da Memória, Natal, RN, 2009. Disponível em: <http://centenario.ifrn.edu.br>. Acesso em: 18 mar. 2018.

LAVILLE, Cristian; DIONNE, Jean. A construção do saber: manual de metodologia da pesquisa em ciências humanas. Porto Alegre: EDUFMG, 1999.

MEDEIROS, Arilene Lucena de. A forja e a pena: Técnica e humanismo na trajetória da Escola de Aprendizes Artífices de Natal à Escola Técnica Federal do Rio Grande do Norte. Natal: Editora IFRN, 2011.

PEGADO, Erika Araújo da Cunha. Reflexos da História no Cotidiano Institucional desde a Escola de Aprendizes e Artífices até o CEFET-RN. In: (Org.). A trajetória do CEFET-RN desde a sua criação no início do século XX ao alvorecer do século XXI, Natal: IFRN Editora, 2. ed., 2010. 132 p. Disponível em: <http://portal.ifrn.edu.br/pesquisa/editora/livros-em-pdf/atrajetoria-do-cefet-rn>. Acesso em: 18 mar. 2018.

SEVERINO, Antônio Joaquim. Metodologia do Trabalho Científico. 23 ed. São Paulo: Cortez, 2007.

SILVA, Luisa de Marilac de Castro. Entre o desejável e o possível: a Escola de Aprendizes Artífices do Rio Grande do Norte: 1909-1937. 2016, 160f. Tese (Doutorado em Educação)- Universidade Federal do Rio Grande do Norte, 2016. Disponível em: <http://repositorio.ufrn.br:8080/jspui/bitstream/123456789/21547/1/LuisaDeMa rilacDeCastroSilva_TESE.pdf>. Acesso em: 20 mar. 2018.

SILVA, Maria da Guia. Escola para os filhos dos outros: trajetória histórica da Escola Industrial de Natal (1942-1968). 2012, 224f. Tese (Doutorado em Educação)- Universidade Federal do Rio Grande do Norte, $2012 . \quad$ Disponível em: <https://repositorio.ufrn.br/jspui/handle/123456789/14403>. Acesso em: 18 mar. 2018.

SOBOTTKA, Emil Albert. Por que se faz políticas sociais no Brasil? Notas sobre estratégias de legitimação nos últimos dois governos federais. 
Civitas - Revista de Ciências Sociais, Rio Grande do Sul, v. 6, n. 1, p. 79-93, janeiro, 2006. em: <http://revistaseletronicas.pucrs.br/ojs/index.php/civitas/article/view/23/6948>. Acesso em: 01 abr. 2018. 